\title{
Benefits, challenges and ethical principles associated with implementing noninvasive prenatal testing: a Delphi study
}

\author{
Charles Dupras PhD, Stanislav Birko BSc, Aliya Affdal MSc, Hazar Haidar PhD, Marie-Eve Lemoine MSc, \\ Vardit Ravitsky PhD
}

\section{Abstract}

Background: Noninvasive prenatal testing is a recent technology that provides some genetic information about the fetus through the analysis of cell-free fetal DNA circulating in maternal blood. We aimed to identify the benefits, challenges and guiding ethical principles most relevant to the clinical integration of noninvasive prenatal testing in Canada, according to experts throughout the country.

Methods: We conducted a 3-round Delphi study involving Canadian experts of contemporary discussions about the ethical and societal implications of prenatal testing and genomic technologies. In round 1, we asked participants to identify clinical benefits and challenges related to the implementation of noninvasive prenatal testing in Canada, and the ethical principles they think should guide it. In round 2, we asked participants to select the most important elements stated by their peers. In round 3, participants were informed of the aggregated results from round 2 , and invited to revise or confirm their selection.

Results: Round 1 had a participation rate of $20.2 \%$, and involved 61 participants. Subsequent rounds 2 and 3 had retention rates of $95.1 \%(n=58)$ and $84.5 \%(n=49)$, respectively. Through these discussions, we identified 3 lists of benefits $(n=10)$, challenges $(n=$ 27 ), and ethical principles $(n=16)$ prioritized by Canadian experts as being most relevant to the implementation of noninvasive prenatal testing in Canada.

Interpretation: Although multiple and diverse potential issues were identified, Canadian experts agreed on 2 sets of requirements for the responsible implementation of noninvasive prenatal testing in Canada. Interdisciplinary appraisals may be instrumental to responsible policy-making related to the implementation of noninvasive prenatal testing in Canada.

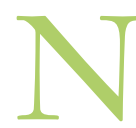
oninvasive prenatal testing allows genetic testing through the analysis of cell-free fetal DNA circulating in maternal blood. Although not as accurate as diagnostic tests such as amniocentesis or chorionic villus sampling, noninvasive prenatal testing may provide important benefits for pregnant women and their families. In contrast with invasive methods, it carries no risk of miscarriage. In addition, it can be done in early pregnancy (weeks 10-11) and has better detection rates than current first-tier screening methods. The test is thus being gradually implemented worldwide, and is currently available in more than 60 countries, ${ }^{1}$ commercially in most, and covered by public funding in some. To date, in Canada, Ontario and British Columbia offer public funding for noninvasive prenatal testing, but only under specific conditions. ${ }^{2,3}$ More recently, the Quebec Ministry of Health announced that it will cover the cost of its use in high-risk pregnancies. ${ }^{4}$

Scholars and advocacy groups have expressed concerns regarding the potential consequences of "routinizing" noninvasive prenatal testing. ${ }^{5,6}$ These concerns include an erosion of free and informed consent, in addition to the possibility of increased rates of pregnancy termination, which could lead to decreased prevalence of certain genetic conditions and may lead to decreased medical and social support for people and families living with these conditions. ${ }^{7-10}$ Thus, it is important to empirically assess the ethical and societal acceptability of noninvasive prenatal testing's clinical implementation and coverage through public funding, to determine that they reflect the interests, needs and values of Canadians. ${ }^{11}$ Such decisions should be based on robust evidence regarding costeffectiveness, ${ }^{12}$ and on the views and preferences of stakeholders. ${ }^{13}$ In addition, we argue that these decisions should be informed by the evolving perspectives of Canadian experts on ethical and societal issues related to prenatal testing and

Competing interests: None declared.

This article has been peer reviewed.

Correspondence to: Charles Dupras, charles.dupras2@mcgill.ca CMAJ Open 2018. DOI:10.9778/cmajo.20180083 
genomic technologies. In this study, we aimed to identify the most important benefits, challenges and guiding ethical principles regarding the clinical integration of noninvasive prenatal testing in Canada, according to such experts.

\section{Methods}

The Ethical Delphi technique, an "approach for characterizing ethical issues raised by the use of novel biotechnologies," was ideally suited to the aim of this study. ${ }^{14}$ The classical Delphi method consists of surveying a panel of experts on a given topic, providing the panel with aggregate results, and obtaining feedback on the results in subsequent rounds. The method promotes an honest, evolving and constructive exchange between people from diverse backgrounds and aims to identify areas of agreement and disagreement regarding emerging areas of knowledge. ${ }^{15,16}$ It is a semianonymous method in which research participants are known to investigators but not to one another. Preserving such anonymity provides the respondents with the freedom to change their opinion from one round to the next, rather than defending a locked-in position with their name attached to it. ${ }^{17} \mathrm{We}$ conducted a 3-round Ethical Delphi study with participants with a diversity of experience with, knowledge of and perspectives on the ethical and societal aspects of prenatal testing and genomic technologies.

\section{Recruitment of the expert panel}

We identified people who had been actively involved in previous scholarly (e.g., academic literature) or public (e.g., newspaper articles) discussions on the ethical and societal aspects of prenatal testing and genomic technologies, in addition to relevant professional or advocacy activities in Canada for at least 3 years, as potential participants. We recruited participants from 4 groups: health care professionals, researchers in social sciences and humanities, patient or disability rights advocates, and cultural or religious community advocates. Before completing round 1, participants were asked to confirm that they indeed identified as belonging to one of the 4 groups, and to specify their professional, academic or advocacy expertise. We aimed to recruit $10-15$ respondents per group, ${ }^{17,18}$ and tried to ensure a response rate of more than $70 \%$ in each round to minimize selective participant retention bias. ${ }^{19,20}$ Special efforts were made during recruitment to account for language distribution, sex ratio and geographic representation. Participants were invited to participate by email, and were not remunerated for their involvement.

\section{Questionnaires and analysis}

In round 1 (May-August 2015), research participants were asked to provide demographic and other relevant information about themselves. Using open-ended questions, we invited them to state, in their own words, the most important "clinical benefits," "ethical, legal, and social issues and concerns" and "moral principles, social norms and values" related to the implementation of noninvasive prenatal testing in Canada. We formulated these questions as broadly as possible to avoid orienting participants' responses from the outset. For the same reason, we deliberately avoided importing concerns from the existing literature at any round of the study. Upon completion of round 1, two reseachers (Birko and Dupras) independently assessed participants' responses and clustered qualitative data using NVivo 10 (QSR International).

Following the process outlined by Burnard, ${ }^{21}$ we generated 3 lists of nonredundant benefits, challenges and guiding ethical principles relevant to the implementation of noninvasive prenatal testing in Canada. The second round (January-April 2016) questionnaire was created based on the responses and exact terminology employed by research participants in round 1. Using multiple-choice questions, we asked participants to select the most important benefits, challenges and principles that had been formulated by their peers, according to their own opinion and their estimation of public opinion. The third round (September-December 2016) consisted of an identical set of multiple-choice questions, complemented by a quantitative presentation of the aggregate responses from round 2 . Informed by the panel's position, participants had the opportunity to revise or confirm their responses. The 3 rounds were piloted by Haidar and Lemoine for face and content validity.

\section{Ethics approval}

We obtained ethics approval from the University of Montréal Comité d'éthique de la recherche en santé (\#14-104-CERES-D) before each round.

\section{Results}

We identified a total of 302 potential participants, 61 of whom completed round 1 (initial participation rate $20.2 \%$ ). The makeup of the panel included 17 health care professionals, 17 researchers, 17 patient or disability rights advocates, and 10 cultural or religious community advocates (Tables 1 and 2). Of the 61 experts who completed round 1, 95.1\% completed round 2 ( $n=58 / 61)$, of whom $84.5 \%$ completed round $3(n=49 / 58)$. The resulting overall retention rate was $80.3 \%(n=49 / 61)$, with rates considerably higher than the $70 \%$ per round usually recommended for Delphi studies. ${ }^{22}$ Among the participants who completed all 3 rounds, $30.6 \%$ were health care professionals $(n=15 / 49), 28.6 \%$ were researchers in social sciences and humanities ( $n=14 / 49), 28.6 \%$ were patient or disability rights advocates $(n=14 / 49)$, and $12.2 \%$ were cultural or religious community advocates $(n=6 / 49)$. The initial panel was highly heterogeneous in terms of participants' opinions about the "overall acceptability" of noninvasive prenatal testing in Canada: $55.1 \%(n=35 / 61)$ perceived the test to be mostly acceptable (score 1,2 or 3 on 7 -point Likert scale), and $28.6 \%(n=17 / 61)$ viewed it as mostly unacceptable (score 5, 6 or 7). Such diversity of opinion was important, given our objective of characterizing as many different views and concerns as possible.

Participants identified 10 nonredundant benefits, 27 challenges and 16 guiding ethical principles relevant to the implementation of noninvasive prenatal testing in Canada. Table 3 presents the final lists of prioritized benefits, challenges and principles, as ranked by the panel after round 3 . 


\section{Interpretation}

Throughout the 3 rounds, we paid special attention to reporting the exact terminology employed by participants when stating benefits, challenges and principles. Our study thus has the advantage of offering a detailed landscape of the vocabulary used in practice by experts from diverse epistemologic standpoints. Although many participants assigned value to noninvasive prenatal testing because of its increased accuracy in contrast to current first-tier screening methods, the panel largely agreed that the test's most salient benefits arise when comparing noninvasive prenatal testing to current second-tier diagnostic methods (e.g., no risk of miscarriage, noninvasiveness and results available earlier in the pregnancy). Our study thus confirms the main clinical benefits of noninvasive prenatal testing usually expected and discussed in the literature (safer, easier, earlier). ${ }^{11}$

The panel expected the public to agree with the high ranking of these benefits, but believed Canadians could also be attracted by the idea that the new test provides more information that is potentially useful for decision-making (Appendix 1, available at www.cmajopen.ca/content/6/4/ E513/suppl/DC1]). After carefully analyzing challenges and principles, we argue that our study points to 2 sets of requirements that should be prioritized according to Canadian experts: ethical requirements to actively promote free

\begin{tabular}{|c|c|c|c|}
\hline \multirow[b]{2}{*}{ Field of expertise or group represented } & \multicolumn{3}{|c|}{ No. of participants } \\
\hline & Round 1 & Round 2 & Round 3 \\
\hline Health care professional & 17 & 16 & 15 \\
\hline Gynecologist and obstetrician & 4 & 3 & 15 \\
\hline Genetic counsellor & 3 & 3 & 3 \\
\hline Neonatalogist & 3 & 3 & 3 \\
\hline Medical geneticist & 2 & 2 & 3 \\
\hline Midwife & 1 & 1 & 1 \\
\hline Nurse & 1 & 2 & 2 \\
\hline Pediatrician & 1 & 1 & 1 \\
\hline Other & 2 & 2 & 1 \\
\hline Social science and humanities researcher & 17 & 17 & 14 \\
\hline History & 4 & 4 & 4 \\
\hline Law & 3 & 3 & 2 \\
\hline Bioethics & 2 & 2 & 2 \\
\hline Sociology & 1 & 1 & 1 \\
\hline Anthropology & 1 & 1 & 0 \\
\hline Philosophy & 1 & 1 & 0 \\
\hline Other & 5 & 5 & 5 \\
\hline Patients or disability rights advocate* & 17 & 16 & 14 \\
\hline Association promoting social values & 6 & 6 & 6 \\
\hline Association specific to Down syndrome & 4 & 4 & 4 \\
\hline Association specific to an other condition & 2 & 1 & 0 \\
\hline Involved in more than one association & 2 & 2 & 2 \\
\hline Not affiliated to any association & 3 & 3 & 2 \\
\hline Cultural or religious community advocate & 10 & 9 & 6 \\
\hline Islam & 3 & 3 & 2 \\
\hline Christianity & 2 & 2 & 2 \\
\hline Judaism & 2 & 2 & 1 \\
\hline First Nations & 1 & 0 & 0 \\
\hline Other & 2 & 2 & 1 \\
\hline Total & 61 & 58 & 49 \\
\hline
\end{tabular}


and informed decision-making for prospective parents, and societal requirements to protect and promote the rights and interests of vulnerable individuals.

Participants unambiguously stressed how challenging offering adequate counselling to patients can be, and yet largely

\begin{tabular}{|c|c|c|c|}
\hline \multirow[b]{2}{*}{ Characteristic } & \multicolumn{3}{|c|}{ Participants, \% } \\
\hline & $\begin{array}{l}\text { Round } 1 \\
n=61\end{array}$ & $\begin{array}{c}\text { Round } 2 \\
n=58\end{array}$ & $\begin{array}{c}\text { Round } 3 \\
n=49\end{array}$ \\
\hline \multicolumn{4}{|l|}{ Demographic } \\
\hline \multicolumn{4}{|l|}{ Language* $^{*}$} \\
\hline English & 70.5 & 70.7 & 69.4 \\
\hline French & 26.2 & 25.9 & 26.5 \\
\hline \multicolumn{4}{|l|}{ Sex } \\
\hline Female & 55.7 & 56.9 & 57.1 \\
\hline Male & 44.3 & 43.1 & 42.9 \\
\hline \multicolumn{4}{|l|}{ Age, yr } \\
\hline 20-39 & 16.4 & 17.2 & 18.4 \\
\hline $40-59$ & 49.2 & 48.3 & 46.9 \\
\hline $60-79$ & 32.8 & 32.8 & 34.7 \\
\hline 80-99 & 1.6 & 1.7 & - \\
\hline \multicolumn{4}{|l|}{ Country of birth } \\
\hline Canada & 68.9 & 67.2 & 69.4 \\
\hline \multicolumn{4}{|l|}{ Province of residence $†$} \\
\hline Quebec & 39.3 & 39.6 & 38.8 \\
\hline Ontario & 26.2 & 25.9 & 26.5 \\
\hline Alberta & 9.8 & 10.3 & 8.2 \\
\hline British Columbia & 8.2 & 8.6 & 8.2 \\
\hline Manitoba & 6.6 & 5.2 & 6.1 \\
\hline Nova Scotia & 3.3 & 3.4 & 4.1 \\
\hline \multicolumn{4}{|l|}{ Degree completed $\ddagger$} \\
\hline Doctoral & 60.7 & 60.3 & 61.2 \\
\hline Masters & 14.8 & 15.5 & 18.4 \\
\hline Bachelor & 11.5 & 12.1 & 10.2 \\
\hline College & 11.5 & 10.3 & 10.2 \\
\hline \multicolumn{4}{|l|}{ Potentially influencing factor } \\
\hline $\begin{array}{l}\text { Having a child living with a } \\
\text { disability }\end{array}$ & 23.0 & 22.4 & 24.5 \\
\hline $\begin{array}{l}\text { Knowing a child living with a } \\
\text { disability }\end{array}$ & 86.9 & 86.2 & 85.7 \\
\hline Living with a disability & 8.2 & 8.6 & 8.2 \\
\hline Experienced prenatal screening & 47.5 & 43.1 & 44.9 \\
\hline Experienced prenatal diagnosis & 18.0 & 17.2 & 16.3 \\
\hline Disclosed a commercial interest & 1.6 & 1.7 & 2.0 \\
\hline
\end{tabular}

agreed on the high importance of informed decision-making in the context of prenatal care. Our findings thus resonate with the literature, wherein concerns are expressed as to the potential impact on informed decision-making in terms of implementing noninvasive prenatal testing as "just another blood test" ${ }^{\text {"3-26 and }}$ advocating the active promotion of women's reproductive autonomy. ${ }^{27-30}$ In addition to protecting free choice, participants underscored the need to ensure the appropriate conditions for evidence-based decision-making. In this respect, they highlighted the difficulty of ensuring the adequate education of health professionals about new prenatal testing technologies and their potential ethical and societal implications. Additional empirical studies will be helpful to identify the needs and preferences of health professionals regarding continuing training.

The term "autonomy" did not rank very highly in the final list of principles generated by the participants. This concept may have been perceived as too vague by most participants, or not properly reflecting what is truly at stake with the arrival of noninvasive prenatal testing in Canada. The term "consent" also ranked surprisingly low on the list of challenges, suggesting that although Canadian experts value informed choice, they may believe that procedural modalities of signed consent forms are insufficient to adequately promote it. ${ }^{31}$ In the context of noninvasive prenatal testing, promoting reproductive autonomy and protecting consent for prospective parents may instead require enhanced training of health care professionals regarding how best to communicate new testing options to patients, and the importance of understanding individual patients' preferences. Preventing increased pressure to test and pressure to terminate - anticipated consequences of implementing noninvasive prenatal testing in routine prenatal care - is particularly crucial, given our participants' estimation of free choice ranking first according to Canadians (Appendix 1). In the literature, such concerns have consistently been formulated by disability rights advocates, who fear that the emergence of new medical and social norms in prenatal testing may impose coercive pressures on pregnant women to test and terminate affected pregnancies under the guise of "responsible motherhood," thus impeding the voluntary nature of their individual choices., $832-36$

Some empirical studies have shown that health care professionals tend to be in favour of testing and terminating affected pregnancies and may thus exercise subtle yet considerable influence on their patient's decision-making process and final choice. ${ }^{34,37}$ At the same time, some patients may expect clear recommendations from their health care provider, deliberately and admittedly intending to follow them..$^{9}$ To address the imperative of protecting free choice through the provision of relevant, adequate and sufficient information, ${ }^{38}$ different strategies exist, such as nondirective counselling (focused on the patient's decisional authority) or shared decision-making (focused on open discussion of personal values and opinions). ${ }^{39,40}$ These strategies can increase people's freedom of choice by improving their understanding of available options. ${ }^{41-43}$

More than half of the participants feared that the implementation of noninvasive prenatal testing may lead to increased discrimination against people with disabilities. Many also shared concerns over eugenics and a potential decrease in social support 
for people with disabilities in the future. They estimated that the threat of eugenics ranks even higher in public opinion (Appendix 1). Perhaps in response to these challenges, the principle of respect for human dignity was perceived by the panel as very important for guiding the implementation of noninvasive prenatal testing in Canada. Many participants underscored the need to continuously promote respect for diversity, and solidarity with individuals living with conditions for which the test screens. These principles point to the societal imperative of being actively committed to the welfare of vulnerable groups. Disability scholarship literature has been useful in highlighting areas of needed improvement in this regard. ${ }^{44-46}$

Although the cost of implementing noninvasive prenatal testing did not rank highly, most participants stressed the importance of ensuring equitable access to the test. Indeed, if it is available only to people who can afford the cost, already vulnerable people or populations could be unfairly disadvantaged by not being offered the same opportunity to manage risks such as miscarriage associated with publicly covered invasive techniques (e.g., amniocentesis) and the perceived burden (e.g., psychological, financial) of raising a child with a severe genetic condition. $^{40,47}$ It is worth noting that the cost of implementing noninvasive prenatal testing was estimated to rank first as a challenge in public opinion. However, whether the public is expected to be concerned about the economic burden being imposed on prospective parents (private funding) or on the health care budget (public funding) remains unclear. Empirical studies will be helpful in determining the specific criteria (e.g., level of risk, conditions tested for, funding model) the Canadian public and stakeholders think satisfy the principle of equitable access.

\section{Limitations}

We experienced difficulty in recruiting cultural or religious community advocates who had previously expressed their views regarding prenatal testing and genomic technologies. Few such people may have considered themselves sufficiently knowledgeable about noninvasive prenatal testing and thus competent to engage in the study. The resulting lower number of participants

\begin{tabular}{|c|c|c|}
\hline Factor & Participants, \% & $\begin{array}{c}\text { Change, \% } \\
\text { (R3-R2) }\end{array}$ \\
\hline \multicolumn{3}{|l|}{ Benefits } \\
\hline 1. No risk of miscarriage & 83.7 & +13.0 \\
\hline 2. Noninvasiveness & 63.3 & +1.2 \\
\hline 3. Results available earlier in the pregnancy & 53.1 & +6.3 \\
\hline 4. Requires only a blood draw & 42.9 & +5.0 \\
\hline 5. Increased accuracy & 30.6 & +8.2 \\
\hline 6. Enhances prospective parents' ability to prepare & 24.5 & -11.7 \\
\hline 7. Decreases anxiety for prospective parents & 16.3 & -7.8 \\
\hline 8. Provides more information potentially useful for decision-making & 16.3 & -25.1 \\
\hline 9. Answers specific needs & 10.2 & -3.6 \\
\hline 10. Potential to expand conditions tested & 4.1 & -8.0 \\
\hline \multicolumn{3}{|l|}{ Challenges } \\
\hline 1. Adequate counselling of patients & 79.6 & +19.3 \\
\hline 2. Pressure to test & 67.3 & +10.4 \\
\hline 3. Adequate education of health professionals & 65.3 & +10.1 \\
\hline 4. Discrimination against people with disabilities & 59.2 & +10.9 \\
\hline 5. Pressure to terminate & 55.1 & +10.3 \\
\hline 6. Eugenics & 46.9 & +2.1 \\
\hline 7. Potential decrease in social support for people with disabilities & 44.9 & +1.8 \\
\hline 8. Routinization of prenatal testing & 38.8 & +0.9 \\
\hline 9. Stigmatization of the parents of children living with the tested conditions & 38.8 & -0.9 \\
\hline 10. Accuracy of the test & 34.7 & -1.5 \\
\hline 11. Decrease in social diversity & 34.7 & +5.4 \\
\hline 12. Adequate professional guidelines & 32.7 & -5.2 \\
\hline 13. Consent & 32.7 & +1.7 \\
\hline 14. Cost of implementation & 32.7 & -1.8 \\
\hline
\end{tabular}




\begin{tabular}{|c|c|c|}
\hline Factor & Participants, \% & $\begin{array}{c}\text { Change, \% } \\
\text { (R3-R2) }\end{array}$ \\
\hline 15. Selective pregnancy termination & 32.7 & -5.2 \\
\hline 16. What conditions to test & 30.6 & +8.2 \\
\hline 17. Increased number of terminated pregnancies & 30.6 & -0.4 \\
\hline 18. Conflicts of interest linked to commercialization & 28.6 & -2.4 \\
\hline 19. Misperceptions of the reliability testing & 28.6 & -11.1 \\
\hline 20. Existence of adequate policies & 28.6 & -5.9 \\
\hline 21. Respect of human rights & 26.5 & -4.5 \\
\hline 22. Access-related issues & 24.5 & -1.4 \\
\hline 23. Increased anxiety for prospective parents & 18.4 & -7.5 \\
\hline 24. Conflict with religious values & 14.3 & +2.2 \\
\hline 25. Assigning responsibility to care for the child & 8.2 & -0.4 \\
\hline 26. Utility of the test & 8.2 & -12.5 \\
\hline 27. Confidentiality of the results & 2.0 & -13.5 \\
\hline \multicolumn{3}{|l|}{ Principles } \\
\hline 1. Informed decision-making & 81.6 & +2.3 \\
\hline 2. Evidence-based decision-making & 59.2 & +8.9 \\
\hline 3. Respect for human dignity & 53.1 & +2.3 \\
\hline 4. Equitable access & 51.0 & +7.9 \\
\hline 5. Free choice & 51.0 & -0.7 \\
\hline 6. Fair resource allocation & 46.9 & +0.3 \\
\hline 7. Respect for diversity & 44.9 & +1.8 \\
\hline 8. Solidarity with people living with the tested conditions & 44.9 & -10.3 \\
\hline 9. Human rights & 40.8 & +0.6 \\
\hline 10. Equality between persons & 38.8 & +6 \\
\hline 11. Nonmaleficence (do not harm) & 36.7 & -6.4 \\
\hline 12. Autonomy & 30.6 & -7.3 \\
\hline 13. Protection of privacy & 28.6 & -5.9 \\
\hline 14. Sanctity of life & 28.6 & +4.5 \\
\hline 15. Inclusiveness & 22.4 & -6.9 \\
\hline 16. Beneficence & 18.4 & -5.7 \\
\hline
\end{tabular}

in this group, however, should not be perceived as impeding the scientific validity of the results. Our objective was not to compare the views of diverse groups of experts and search for statistically significant associations, but rather to shed light on a diversity of perspectives regarding noninvasive prenatal testing. The specific composition of our panel of experts and the associated limitations should be considered when interpreting the results and their meaning for Canadian policy.

Being pregnant or living with a condition identified through noninvasive prenatal testing were not considered sufficient criteria for participation in our study. Empirical studies with Canadian stakeholders (e.g., PEGASUS surveys involving pregnant women and their partners) will be instrumental in guiding policy-making. ${ }^{13}$ However, we did not consider such stakehold- ers to be experts for the purposes of this study. As reported in Table 2, female participants represented more than half of the panel in each round, with $44.9 \%$ of the final panel $(n=22 / 49)$ having experienced prenatal testing themselves. In addition, considerable numbers of participants reported either knowing a child $(n=42 / 49)$, having a child $(n=12 / 49)$ or living themselves $(n=4 / 49)$ with a disability.

\section{Conclusion}

In addition to the ethical and societal considerations discussed here, it is worth noting that some of the issues highlighted by smaller proportions of participants in this study are also informative and should be considered. This is particularly important if we care to consider the voices of people with specific 
vulnerabilities who, owing to their unique experiences of exclusion, may be more aware of and sensitive to particular ethical and societal issues such as the possibility of decreased social diversity that may follow increased selective pregnancy termination. Potential conflicts of interest linked to the commercialization of noninvasive prenatal testing is another challenge that should be addressed. Otherwise, in the long term, the rise of distrust by some people toward the medical community could further impede effective communication about prenatal testing options. Interdisciplinary appraisals of such issues may be instrumental to responsible policy-making related to the implementation of noninvasive prenatal testing in Canada.

\section{References}

1. Chandrasekharan S, Minear MA, Hung A, et al. Noninvasive prenatal testing goes global. Sci Transl Med 2014;6:231fs 15 .

2. Vanstone M, Yacoub K, Giacomini M, et al. Women's experiences of publicly funded non-invasive prenatal testing in Ontario, Canada: considerations for health technology policy-making. Qual Health Res 2015;25:1069-84.

3. NIPT funding available for eligible women at high risk. Vancouver: Perinatal Services BC; 2016. Available: www.perinatalservicesbc.ca/about/news-stories/ stories/non-invasive-prenatal-testing-(nipt) (accessed 2017 Dec. 1).

4. Dion M. Trisomie: premier financement public à grande échelle pour un test d'ADN. Radio Canada 2018 Apr. 22 (updated 2018 Apr. 23). Available: https://ici. radio-canada.ca/nouvelle/1096429/trisomie-test-adn-financement-public-quebec (accessed 2018 Aug. 16)

5. Gekas J, Langlois S, Ravitsky V, et al. Non-invasive prenatal testing for fetal chromosome abnormalities: review of clinical and ethical issues. Appl Clin Genet 2016;9:15-26.

6. Birko S, Lemoine M-E, Nguyen MT, et al. Moving towards routine noninvasive prenatal testing (NIPT): challenges related to women's autonomy. OBM Genet 2018;2:18.

7. Hall A, Bostanci A, John S. Ethical, legal and social issues arising from cell-free fetal DNA technologies. Appendix III to the report: Cell-free fetal nucleic acids for noninvasive prenatal diagnosis. Cambridge (UK): PHG Foundation; 2009. Available: www.phgfoundation .org/download/ffdna/ffDNA_appendix.pdf(accessed 2017 Dec. 1).

8. Kaposy C. A disability critique of the new prenatal test for Down syndrome. Kennedy Inst Ethics 7 2013;23:299-324.

9. Tischler R, Hudgins L, Blumenfeld YJ, et al. Noninvasive prenatal diagnosis: pregnant women's interest and expected uptake. Prenat Diagn 2011;31: 1292-9.

10. van Schendel RV, Kleinveld JH, Dondorp WJ, et al. Attitudes of pregnant women and male partners towards non-invasive prenatal testing and widening the scope of prenatal screening. Eur 7 Hum Genet 2014;22:1345-50.

11. Haidar H, Dupras C, Ravitsky V. Non-invasive prenatal testing: review of ethical, legal and social implications. BioéthiqueOnline 2016;5:1-14.

12. Murdoch B, Ravitsky V, Ogbogu U, et al. Non-invasive prenatal testing and the unveiling of an impaired translation process. 7 Obstet Gynaecol Can 2017;39:10-7.

13. About the project. PEGASUS: PErsonalized Genomics for prenatal Aneuploidy Screening USing maternal blood (2013-2017). Québec: Centre de recherche du CHU de Québec et Université Laval, Hôpital Saint-François d'Assise. Available: http://pegasus-pegase.ca/pegasus/about-the-project/ (accessed 2018 Aug. 16).

14. Millar K, Thorstensen E, Tomkins S, et al. Developing the ethical Delphi. $\mathcal{f}$ Agric Environ Ethics 2007;20:53-63.

15. Goodman CM. The Delphi technique: a critique. 7 Adv Nurs 1987;12:729-34.

16. Dalkey N. The Delphi method: an experimental study of group opinion. Santa Monica (CA): Rand Co.; 1969.

17. Delbecq AL, Van de Ven AH, Gustafson DH. Group techniques for program planning: a guide to nominal group and Delphi processes. Glenview (IL): Scott, Foresman; 1975.

18. Skulmoski GJ, Hartman FT, Krahn J. The Delphi method for graduate research. 7 Inf Technol Educ 2007;6:1-21.

19. Walker AM, Selfe J. The Delphi method: a useful tool for the allied health researcher. Br 7 Ther Rebabil 1996;3:677-81.

20. Sumsion T. The Delphi technique: an adaptive research tool. Br 7 Occup Ther 1998;61:153-6

21. Burnard P. A method of analysing interview transcripts in qualitative research. Nurse Educ Today 1991;11:461-6.

22. Hasson F, Keeney S, McKenna H. Research guidelines for the Delphi survey technique. 7 Adv Nurs 2000;32:1008-15.

23. Lewis C, Silcock C, Chitty LS. Non-invasive prenatal testing for Down's syndrome: pregnant women's views and likely uptake. Public Health Genomics 2013;16:223-32.
24. Lewis C, Hill M, Chitty LS. A qualitative study looking at informed choice in the context of non-invasive prenatal testing for aneuploidy. Prenat Diagn 2016;36:875-81.

25. van Schendel RV, van El CG, Pajkrt E, et al. Implementing non-invasive prenatal testing for aneuploidy in a national healthcare system: global challenges and national solutions. BMC Health Serv Res 2017;17:670.

26. Vanstone M, Cernat A, Nisker J, et al. Women's perspectives on the ethical implications of non-invasive prenatal testing: a qualitative analysis to inform health policy decisions. BMC Med Ethics 2018;19:27.

27. Benn P, Cuckle H, Pergament E. Non-invasive prenatal testing for aneuploidy: current status and future prospects. Ultrasound Obstet Gynecol 2013;42:15-33.

28. Hewison J. Psychological aspects of individualized choice and reproductive autonomy in prenatal screening. Bioethics 2015;29:9-18.

29. Chen A, Tenhunen H, Torkki P, et al. Considering medical risk information and communicating values: a mixed-method study of women's choice in prenatal testing. PLoS One 2017;12:e173669.

30. Lewis C, Silcock C, Chitty LS. Non-invasive prenatal testing for Down's syndrome: pregnant women's views and likely uptake. Public Health Genomics 2013;16:223-32.

31. Seavilleklein V. Challenging the rhetoric of choice in prenatal screening. Bioethics 2009;23:68-77.

32. Asch A, Barlevy D. Disability and genetics: a disability critique of pre-natal testing and pre-implantation genetic diagnosis (PGD). In: Encyclopedia of Life Science. Chichester (UK): John Wiley \& Sons Ltd.; 2012.

33. Ho A. Relational autonomy or undue pressure? Family's role in medical decision-making. Scand 7 Caring Sci 2008;22:128-35.

34. Klein DA. Medical disparagement of the disability experience: empirical evidence for the "expressivist objection". A7OB Prim Res 2011;2:8-20.

35. Wasserman D, Asch A. Reply to Nelson. Camb Q Healthc Ethics 2007;16:478-82

36. Ravitsky $\mathrm{V}$. The shifting landscape of prenatal testing: between reproductive autonomy and public health. Hastings Cent Rep 2017;47(Suppl 3):S34-40.

37. Madeo AC, Biesecker BB, Brasington C, et al. The relationship between the genetic counseling profession and the disability community: a commentary. Am 7 Med Genet A 2011;155A:1777-85.

38. García E, Timmermans DR, van Leeuwen E. Rethinking autonomy in the context of prenatal screening decision-making. Prenat Diagn 2008;28:115-20.

39. Sachs A, Blanchard L, Buchanan A, et al. Recommended pre-test counseling points for noninvasive prenatal testing using cell-free DNA: a 2015 perspective. Prenat Diagn 2015;35:968-71.

40. Dondorp W, de Wert G, Bombard Y, et al. Non-invasive prenatal testing for aneuploidy and beyond: challenges of responsible innovation in prenatal screening. Eur 7 Hum Genet 2015;23:1592.

41. Vanstone M, Kinsella EA, Nisker J. Information-sharing to promote informed choice in prenatal screening in the spirit of the SOGC clinical practice guideline: a proposal for an alternative model. 7 Obstet Gynaecol Can 2012;34:269-75.

42. Barnes B. Understanding agency: social theory and responsible action. London (UK): Sage; 2000.

43. Rehmann-Sutter C. Why non-directiveness is insufficient: ethics of genetic decision making and a model of agency. Med Stud 2009;1:113-29.

44. Alderson P. Down's syndrome: cost, quality and value of life. Soc Sci Med 2001;53:627-38.

45. McCarthy $\mathrm{H}$. The disability rights movement: experiences and perspectives of selected leaders in the disability community. Rehabil Couns Bull 2003;46:209-23.

46. Raz A. "Important to test, important to support": attitudes toward disability rights and prenatal diagnosis among leaders of support groups for genetic disorders in Israel. Soc Sci Med 2004;59:1857-66.

47. de Jong A, Dondorp WJ, Frints SG, et al. Advances in prenatal screening: the ethical dimension. Nat Rev Genet 2011;12:657-63.

Affiliations: Center of Genomics and Policy (Dupras) and Institute for Health and Social Policy (Haidar) McGill University; École de santé publique, Université de Montréal (Birko, Affdal, Haidar, Lemoine, Ravitsky), Montréal, Que.

Contributors: All the listed authors have contributed substantially to this article, approved the final version to be published, and agreed to act as guarantors of the results.

Funding: Fonds du Québec pour la recherche - Santé et Culture provided funding for this project (FQRSC, No. 2014-NP-175854).

Acknowledgements: The authors thank all of the participants involved in this study, as well as Dr. Anne-Marie Laberge and Jessica Le Clerc-Blain for insightful comments and suggestions regarding the design of the study and interpretation of the results. The authors also thank Fonds du Québec pour la recherche - Santé et Culture (FQRSC) for providing funding for this project.

Supplemental information: For reviewer comments and the original submission of this manuscript, please see www.cmajopen.ca/content/6/4/ E513/suppl/DC1. 